\title{
Awareness, understanding and use of sodium information labelled on pre-packaged food in Beijing:a cross-sectional study
}

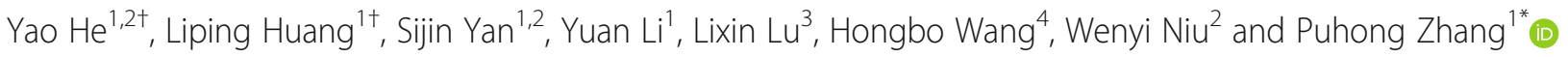

\begin{abstract}
Background: Nutrition labelling has been mandatory for pre-packaged foods since 2013 in China, and sodium is one of the nutrients required for display on the nutritional information panel (NIP). This study aimed to estimate the awareness, understanding of, and use of sodium labelling information among the population in China.

Methods: A cross-sectional survey was carried out in urban Beijing in 2016 on pre-packaged foods. The researchers randomly selected 380 residents from four convenient but disconnected communities and 370 shoppers from four supermarkets owned by different companies and conducted face-to-face interviews. Questions on nutritional knowledge, health attitude, understanding and use of nutritional labels as well as other related factors were assessed.

Results: All of the 380 community residents and 308 of the 370 supermarket shoppers successfully completed the survey. Of those 688 respondents, $91.3 \%$ understood that excessive salt intake was harmful, 19.5\% were aware that sodium content is listed on the NIP, 5.5\% understood the meaning of NRV\% (Percentage of Nutrient Reference Values), 47.7\% did not know the relationship between sodium and salt, and $12.6 \%$ reported they frequently read the label when shopping. Factors for why people were more likely to choose a product because of its low level of salt shown on the label include income level and their level of awareness of the link between salt and diet.

Conclusions: Although the participants had a good understanding of the harmful effects of salt, the awareness, understanding and use of sodium labels was very low in Beijing, and even worse nationwide. Efforts should be taken to educate the public to understand and use the NIP better and design clearer ways of displaying such information, such as front-of pack (FoP) labelling or health-related smartphone applications to improve health and help people make better food choices.
\end{abstract}

Keywords: Sodium, Salt, Nutrition labelling, Awareness, Understanding, Use

\section{Background}

It is well documented that there is a strong relationship between excessive sodium intake and hypertension [1-4]. Sodium differs from salt (sodium chloride). But for the purpose of this paper, we use "sodium" to mean "salt". The implementation of effective salt reduction strategies has been regarded as one of the most cost-effective

\footnotetext{
* Correspondence: zpuhong@georgeinstitute.org.cn

tEqual contributors

${ }^{1}$ The George Institute for Global Health at Peking University Health Science Center, Level 18, Tower B, Horizon Tower, No. 6, Zhichun Road, Haidian District, Beijing 100088, China

Full list of author information is available at the end of the article
}

measures to prevent cardiovascular diseases [5-7]. Member States of the World Health Organization (WHO) have agreed to a global target of a 30\% reduction in population salt intake by 2025 [8]. Salt intake in China is known to be higher than in most other countries $[9,10]$, two or three times higher than the $5 \mathrm{~g}$ daily limit recommended by WHO [11]. Hence, effective salt reduction programs are urgently needed in China.

Pre-packaged processed foods are the major source of salt intake in developed countries and their consumption is rising in many developing countries [10]. Some governments have initiated national approaches to work

(c) The Author(s). 2018 Open Access This article is distributed under the terms of the Creative Commons Attribution 4.0 International License (http://creativecommons.org/licenses/by/4.0/), which permits unrestricted use, distribution, and 
with the food industry to reduce salt in foods by setting salt reduction targets [12-14]. Meanwhile, labelling the amount of sodium and/or salt on the nutrition information panel (NIP) of pre-packaged foods is also among health initiatives to reduce salt. Many countries have added sodium or salt to the list of required nutrients that must be declared on the NIP [15-19]. Some countries, like the US, now highlight the sodium content of food in larger, bold font in black on the label, to draw consumers' attention to the sodium content in pre-packaged food. Although pre-packaged food is not the main source of salt intake in China, the sales and consumption of prepackaged food are increasing very quickly and becoming an important source of salt intake.

The Chinese Government introduced nutrition labelling regulations (General Rules for Nutrition Labelling of Pre-packaged foods - GB 28050-2011) in 2011 and officially implemented the regulation from January 1, 2013 (Fig. 1). These regulations require all prepackaged food, with some exceptions (some fresh foods, alcohol, etc.) to display the energy content $(\mathrm{kJ})$, as well as the amount of protein (g), total fat (g), carbohydrate (g) and sodium (mg) on the NIP. The nutritional values are displayed per $100 \mathrm{~g}$, or per $100 \mathrm{ml}$ or per serving of the food. The sodium label or labelling, in this study, means the sodium concentration shown in mg per $100 \mathrm{~g}$ or per $100 \mathrm{ml}$ or per serving on the NIP, as well as its nutrient reference value (NRV\%).

To our knowledge, few studies have evaluated the awareness, understanding and use of current sodium labelling among Chinese consumers. This cross-sectional study tries to answer these questions and explore the factors associated with them. In this paper, we also recommend changes and improvements to the current sodium labelling system.

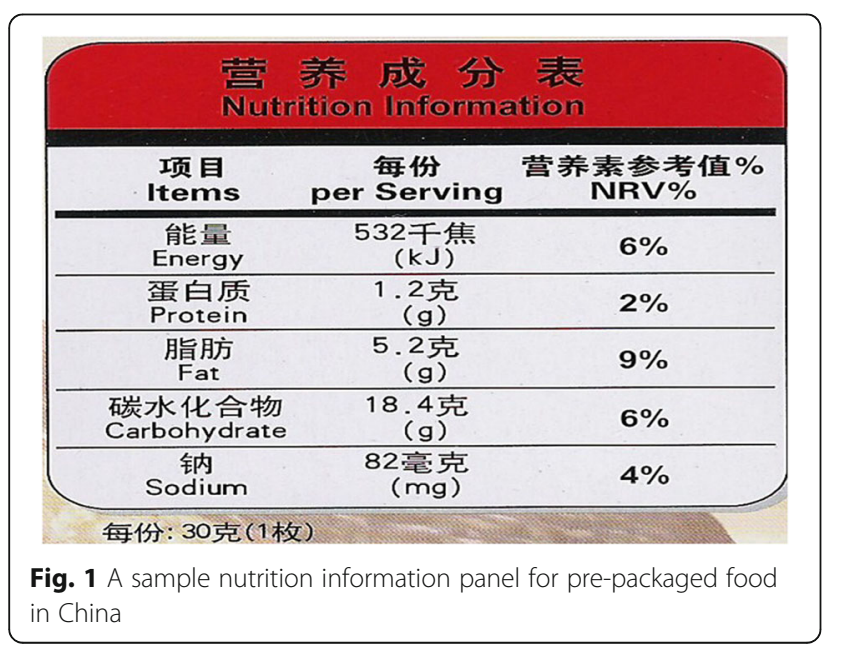

\section{Methods}

\section{Study design and population}

A cross-sectional survey was conducted in Beijing from April to May 2016. Participants were chosen from four convenient but disconnected communities and four supermarkets owned by different companies, with the purpose of representing subgroups with different understanding and use of sodium label due to different ages, education, economic level and personal preference of purchasing and consuming pre-packaged food. Those interviewed in communities were usually older and many retired, with lower incomes and more health problems, while the shoppers at supermarkets were on average, younger in better health and were earning a higher income. In each community, households were visited to find at least 80 adult participants. Only one family member was invited to participate in the survey. If there were two or more family members willing to participate, the person with a higher level of education was selected. In each supermarket, 80 adult shoppers were invited at the entrance to the store to take part in the study. All the participants were interviewed face to face and a standard questionnaire was filled out. A 'non-respondent' was defined as someone who chose not to participate in the survey. People under 18 years old or unable to read for any reason were excluded from participating in the survey.

\section{Data collection}

Self-completed paper-based questionnaires were distributed to all study participants on each site. Participants were requested to complete the questionnaire anonymously and independently after the investigators explained how to fill in the questionnaire. Incomplete questionnaires were excluded from the analysis. Some shoppers declined to participate or to answer all the questions, mainly due to a lack of time to participate.

\section{Questionnaire design and definition}

The questionnaires were designed to collect the following information: 1) Social demographic characteristics, including age, sex, height, weight, education, and household monthly income per capita; 2) Self-reported existing health problems, such as diabetes, hypertension, cardiovascular diseases, dyslipidemia, fatty liver, chronic kidney disease, and food allergies; 3) Awareness of sodium labelling on food packaging, i.e. knowing that "sodium" must be labelled on the NIP as the requirement of government; 4) Understanding of the relationship between sodium and salt, i.e. knowing "salt" is mostly inferred by "sodium" labelled on the NIP; 5) Understanding of NRV\%, the percentage that the content of a nutrient (sodium here) in $100 \mathrm{~g}$ of the food takes up out of the recommended daily intake; 6) Use of the sodium label, defined as checking the 
NIP most of time when shopping, with the purpose of buying the less salt-laden pre-packaged food; and 7) Knowledge, attitude, and behavior of salt intake. In this study, six grams per day of salt was considered the recommended amount as per the Dietary Guidelines for Chinese Residents (2016) in China [20]. Based on series of expert panel discussion, we designed three single-choice questions to evaluate attitudes towards salt intake (awareness of healthy salt levels in food), which was then transformed into an attitude score (Table 1). Salt reduction behavior by asking: "Are you trying to control salt intake during daily life?" which refers to how people reduce salt intake cooking at home, eating out or buying pre-packaged food. (See Additional file 1: Questionnaire for detail).

\section{Statistical analysis}

Mean \pm Standard Deviation (SD) and 95\% Confidence Intervals $(95 \% \mathrm{CI})$ were used to describe continuous variables, and percentage and 95\% CI were used to express categorical variables. The t-test and chi-square test were used to compare continuous variables and categorical variables among different subgroups, respectively. Binary logistic regression analyses by forward stepwise (Likelihood Ratio) method (the entry and removal probabilities for stepwise are 0.05 and 0.1, respectively) were applied in order to assess the factors associated with the participants' awareness, understanding, and use of current sodium labels. Demographic, existing health conditions, knowledge and awareness of healthy amount of saltintake were controlled in the multivariate analyses. SPSS software (Statistical Package for the Social Sciences, Version18.0) was used.

\section{Results}

\section{Characteristics of the participants}

Of the 750 people approached, all the 380 community residents completed the investigation. Of the 370 shoppers,
50 chose not to participate, and 12 more did not fill out the entire questionnaire. The final analysis included 380 (55. 2\%) community residents and 308 (44.8\%) supermarket shoppers. Among the 688 successful respondents, the average age was $39.9 \pm 15.0$, most (78.8\%) were female, more than half $(55.7 \%)$ had junior college or above educational level and around half were suffering from hypertension (51. $6 \%$ ) or cardiovascular disease (40.8\%). More details about the characteristics of the participants in community residents and supermarket shoppers are shown in Table 2.

\section{Knowledge, attitude and behavior on salt intake}

$69.3 \%$ knew the recommended amount of daily salt intake ( $6 \mathrm{~g} /$ day). The majority $(91.3 \%)$ of the participants believed excessive salt intake to be harmful to their health; $76.0 \%$ believed that a reduction in salt intake could help to lower a person's blood pressure; and the average score of attitude towards salt intake was 66.1 out of a perfect 100 points. $67.9 \%$ had the behavior of reducing salt intake in daily life.

\section{Awareness of sodium labels}

The survey found that $19.5 \%$ (95\% CI: $16.5 \%-22.4 \%)$ of participants were aware that sodium was required to be labeled on the NIP of pre-packaged foods. Table 3 shows the awareness of the sodium label in total and subgroups of the study population. In Table 4, the logistic regression analysis indicated that younger people, those with cardiovascular disease and those with a higher level of education and awareness of salt in the diet made people read the labels on food. Table 4 provides more details of the relationship between the taking notice of the sodium content listed on sodium labels and a person's age, educational level and history of cardiovascular disease. Participants with hypertension were not more aware of the sodium label in either univariate or multivariate analyses $(P>0.05)$.

Table 1 Questions, answers and rating principal of participants' attitude towards salt intake

\begin{tabular}{|c|c|c|c|}
\hline No. & Question & Answers & Score ${ }^{a}$ \\
\hline \multirow[t]{4}{*}{1} & \multirow[t]{4}{*}{ Do you believe that excessive salt intake does harm to your health? } & Strongly believe & 3 \\
\hline & & Believe & 2 \\
\hline & & Maybe & 1 \\
\hline & & No & 0 \\
\hline \multirow[t]{4}{*}{2} & \multirow[t]{4}{*}{ Do you believe that reduction in salt intake can help to lower blood pressure? } & Strongly believe & 3 \\
\hline & & Believe & 2 \\
\hline & & Maybe & 1 \\
\hline & & No & 0 \\
\hline \multirow[t]{3}{*}{3} & \multirow[t]{3}{*}{ Do you think it is necessary to control salt intake in pre-packaged foods? } & Very Necessary & 3 \\
\hline & & Necessary & 1.5 \\
\hline & & Not Necessary or Indifferent & 0 \\
\hline
\end{tabular}

${ }^{a}$ The score of attitude towards salt intake was summarized and translated into 100 points for each participant 
Table 2 Characteristics of the participants $(N=688)$

\begin{tabular}{|c|c|c|c|}
\hline & Total population $(\mathrm{N}=688)$ & Community residents $(n=380)$ & Supermarket shoppers $(n=308)$ \\
\hline Sex (Male), \% & 31.2 & $26.3^{* *}$ & 37.3 \\
\hline Age (year), mean \pm SD & $39.9 \pm 15.0$ & $42.5 \pm 16.1^{* *}$ & $36.7 \pm 12.7$ \\
\hline \multicolumn{4}{|l|}{ Educational level, \% } \\
\hline Junior high school or below & 18.6 & $13.9^{* *}$ & 24.4 \\
\hline High or technical school & 25.7 & 23.9 & 27.9 \\
\hline Junior college & 16.3 & 16.1 & 16.6 \\
\hline Undergraduate & 29.8 & 35.5 & 22.7 \\
\hline Graduate or above & 9.6 & 10.5 & 8.4 \\
\hline \multicolumn{4}{|l|}{ Household monthly income (Yuan) per capita, \% } \\
\hline$\leq 5000$ & 59.7 & $57.4^{* *}$ & 62.7 \\
\hline $50,001-10,000$ & 26.3 & 31.6 & 19.8 \\
\hline $10,0001-20,000$ & 10.6 & 7.6 & 14.3 \\
\hline$\geq 20,0001$ & 3.3 & 3.4 & 3.2 \\
\hline $\mathrm{BMI}\left(\mathrm{kg} / \mathrm{m}^{2}\right)$, mean $\pm \mathrm{SD}$ & $23.1 \pm 3.2$ & $23.2 \pm 3.2$ & $23.1 \pm 3.2$ \\
\hline \multicolumn{4}{|l|}{ Existing health problems, \% } \\
\hline Hypertension & 51.6 & $55.0^{*}$ & 47.4 \\
\hline Cardiovascular disease & 40.8 & 43.4 & 37.7 \\
\hline Chronic kidney disease & 12.4 & 13.4 & 11.0 \\
\hline \multicolumn{4}{|l|}{ Knowledge, attitude and behavior towards salt intake } \\
\hline Know recommended daily salt intake, \% & 69.3 & $72.6^{*}$ & 65.3 \\
\hline Score of attitude towards salt intake, mean $\pm S D^{a}$ & $66.1 \pm 19.9$ & $68.2 \pm 19.5^{* *}$ & $63.6 \pm 20.1$ \\
\hline Salt reduction behavior, $\%^{\mathrm{b}}$ & 67.9 & $73.9^{* *}$ & 60.4 \\
\hline
\end{tabular}

\section{Understanding sodium labels}

About half (52.3\%, 95\% CI: $48.6 \%-56.1 \%)$ of the participants understood the relationship between sodium and salt, but only $5.5 \%$ (95\% CI: $3.8 \%-7.2 \%)$ of all participants understood the meaning of NRV\%. Table 3 shows in more detail, the understanding of the relationship between sodium and salt among different groups of people. Because the understanding of NRV\% was too low to conduct an analysis of what affected people's awareness of NIPs, we only conducted logistic regression analysis to examine the factors that affect the understanding of the relationship between sodium and salt. In Table 4, the analysis indicated that participants who had a higher educational level, were more aware of the recommended daily salt intake, and managed their diet better as well as the amount of salt they consumed in food each day, were more likely to understand the relationship between sodium and salt.

\section{Use of the sodium label}

Of all the participants, $12.6 \%$ (95\% CI: $10.2 \%-15.1 \%)$ reported that they frequently or often (most of time) read or checked the sodium label when shopping. Univariate analysis indicates that the following people were more likely to effectively read and act on NIPs: females, community residents (versus supermarket shoppers), those with a higher educational level people with a higher monthly household income per capita plus if people had cardiovascular disease (Table 3). Multivariate analysis shows the similar results (Table 4).

\section{Discussion}

In urban Beijing, our survey found that most participants had a good basic knowledge of salt and its harmful effects on health. Over two thirds of participants were aware of the recommended daily salt intake in China and the majority of them recognized the harm of a diet high in salt, believing that reducing salt intake is beneficial. However, only half of the urban adults know the relationship between "sodium" and "salt", very few people (5.5\%) understood the meaning of NRV\%, less than onefifth $(19.5 \%)$ of them were aware of the sodium label, and only $12.6 \%$ used (read or checked) the sodium label while purchasing pre-packaged foods. Those with a higher income and higher education levels had an increased awareness of and understanding of sodium 
Table 3 The awareness, understanding, and use of sodium labels among participants (\%): univariate analysis

\begin{tabular}{|c|c|c|c|c|}
\hline Factors & $\mathrm{N}$ & Awareness $^{\mathrm{a}}$ & Understanding ${ }^{b}$ & Use $^{c}$ \\
\hline Overall & 688 & 19.5 & 52.3 & 12.6 \\
\hline \multicolumn{5}{|l|}{ Sex } \\
\hline Male & 215 & 15.8 & 47.9 & $8.4^{*}$ \\
\hline Female & 473 & 21.1 & 54.3 & 14.6 \\
\hline \multicolumn{5}{|l|}{ Age } \\
\hline $18-25$ & 117 & $33.3^{* *}$ & 42.7 & 9.4 \\
\hline $26-35$ & 228 & 22.8 & 54.4 & 12.7 \\
\hline $36-45$ & 116 & 20.7 & 55.2 & 14.7 \\
\hline $46-59$ & 149 & 7.4 & 55.7 & 13.4 \\
\hline$\geq 60$ & 78 & 10.3 & 50.0 & 12.8 \\
\hline \multicolumn{5}{|l|}{ Source of participants } \\
\hline Community & 380 & 21.3 & $56.8^{* *}$ & $16.8^{* *}$ \\
\hline Supermarket & 308 & 17.2 & 46.8 & 7.5 \\
\hline \multicolumn{5}{|l|}{ Educational level } \\
\hline Junior high school or below & 128 & $5.5^{* *}$ & $35.2^{* *}$ & $6.3^{*}$ \\
\hline High or technical school & 177 & 12.4 & 39.0 & 11.9 \\
\hline Junior college & 112 & 20.5 & 59.8 & 20.5 \\
\hline Undergraduate & 205 & 27.8 & 63.9 & 13.2 \\
\hline Graduate or above & 66 & 37.9 & 72.7 & 12.1 \\
\hline \multicolumn{5}{|c|}{ Household monthly income per capita } \\
\hline$\leq 5000$ & 411 & $13.6^{* *}$ & $47.0^{* *}$ & $9.2^{*}$ \\
\hline $5001-10,000$ & 181 & 28.2 & 62.4 & 17.7 \\
\hline $10,001-20,000$ & 73 & 26.0 & 54.8 & 16.4 \\
\hline$\geq 20,0001$ & 23 & 34.8 & 60.9 & 21.7 \\
\hline \multicolumn{5}{|l|}{ BMI } \\
\hline$<24$ & 441 & 21.3 & 53.1 & 10.4 \\
\hline $24-27$ & 194 & 15.5 & 51.0 & 17.0 \\
\hline$\geq 28$ & 53 & 18.9 & 50.9 & 15.1 \\
\hline \multicolumn{5}{|l|}{ Hypertension } \\
\hline Yes & 355 & 21.1 & $56.1^{*}$ & 14.1 \\
\hline No & 333 & 17.7 & 48.3 & 11.1 \\
\hline \multicolumn{5}{|l|}{ Cardiovascular Disease } \\
\hline Yes & 281 & $26.7^{* *}$ & $59.1^{* *}$ & $16.0^{*}$ \\
\hline No & 407 & 14.5 & 47.7 & 10.3 \\
\hline \multicolumn{5}{|l|}{ Chronic Kidney Disease } \\
\hline Yes & 85 & $29.4^{*}$ & $63.5^{*}$ & 18.8 \\
\hline No & 603 & 18.1 & 50.7 & 11.8 \\
\hline \multicolumn{5}{|c|}{ Awareness of recommended daily salt intake } \\
\hline Yes & 477 & 21.2 & $59.7^{* *}$ & 14.3 \\
\hline No & 211 & 15.6 & 35.5 & 9.0 \\
\hline \multicolumn{5}{|c|}{ Score of attitude towards salt intake ${ }^{d}$} \\
\hline Higher & 304 & 22.7 & $57.9^{* *}$ & $20.7^{* *}$ \\
\hline Lower & 384 & 16.9 & 47.9 & 6.3 \\
\hline
\end{tabular}

Salt reduction behavior ${ }^{\mathrm{e}}$ 
Table 3 The awareness, understanding, and use of sodium labels among participants (\%): univariate analysis (Continued)

\begin{tabular}{cllll}
\hline Factors & N & Awareness $^{\text {a }}$ & Understanding $^{\text {b }^{*}}$ & Use $^{c}$ \\
\hline Yes & 467 & 19.7 & $58.0^{* *}$ & $15.4^{* *}$ \\
No & 221 & 19.0 & 40.3 & 6.8
\end{tabular}

${ }^{a}$ Proportion of participants aware of sodium label on nutrition information panel

${ }^{b}$ Proportion of participants who understood the relationship between sodium and salt

c Proportion of participants who read or checked the sodium label most of time while shopping

d The score of participants towards salt intake. "Higher" score was defined as above the average, and "Lower" score was defined as below the average

e The behavior of usually controlling the salt intake in daily life

${ }^{*} p<0.05 ;{ }^{* *} p<0.01$, the chi-squared test was used to compare the differences among subgroups

labels. Considering that this was conducted in urban Beijing where people have nearly the highest income and education levels in China, the level of the awareness, understanding of health diets and sodium labels might be less elsewhere in the country.

The high awareness (91.3\%) of about the harmfulness of excessive salt intake found in this study reflects the success of Government's "salt" reduction advocacy. The results showed that, participants with hypertension were no more aware of the "sodium" label than those without hypertension. This might be largely due to the low awareness of the relationship between 'sodium' and 'salt' as well as the low level of awareness of NRV\% and sodium.
In our study, only about one-half (52.3\%) of the participants reported knowing the relationship between salt and sodium. A similar study conducted in Japan in 2012 concluded that few people (only 13.3\%) understood the correlation of $1000 \mathrm{mg}$ sodium in grams of salt (2.50-2. $60 \mathrm{~g})$ [18]. This suggests that the current label of showing salt by sodium content may not be effective in informing consumers of the salt content in food. It would therefore be prudent to update the design and content of the NIP to show salt rather than sodium in order to improve awareness and understanding. This is also suggested by the CODEX Guidelines on Nutrition Labelling [21], and some countries such as UK, have mandatorily required to use "salt" rather than "sodium"

Table 4 Associated factors: awareness, understanding and use of sodium labels. Results of logistic analysis by a stepwise method

\begin{tabular}{|c|c|c|c|c|c|c|}
\hline \multirow[t]{2}{*}{ Final model $^{a}$} & \multirow[t]{2}{*}{$\beta$} & \multirow[t]{2}{*}{$S E^{b}$} & \multirow[t]{2}{*}{$P$ value } & \multirow{2}{*}{$\begin{array}{l}\text { Odds } \\
\text { Ratio }\end{array}$} & \multicolumn{2}{|c|}{$95 \% \mathrm{Cl}$ of $\mathrm{OR}$} \\
\hline & & & & & Lower & Upper \\
\hline \multicolumn{7}{|l|}{ Awareness of sodium label } \\
\hline Age & -0.501 & 0.100 & $<0.001$ & 0.606 & 0.498 & 0.737 \\
\hline Educational level & 0.416 & 0.088 & $<0.001$ & 1.516 & 1.276 & 1.801 \\
\hline Cardiovascular Disease & 0.704 & 0.210 & 0.001 & 2.022 & 1.339 & 3.052 \\
\hline Score of attitude towards salt intake ${ }^{c}$ & 0.020 & 0.006 & $<0.001$ & 1.020 & 1.009 & 1.031 \\
\hline Constant & -3.111 & 0.517 & $<0.001$ & 0.045 & - & - \\
\hline \multicolumn{7}{|l|}{ Understanding of sodium label ${ }^{d}$} \\
\hline Educational level & 0.436 & 0.065 & $<0.001$ & 1.547 & 1.361 & 1.757 \\
\hline Awareness of recommended daily salt intake & 0.937 & 0.183 & $<0.001$ & 2.553 & 1.784 & 3.653 \\
\hline Salt reduction behavior ${ }^{e}$ & 0.512 & 0.178 & 0.004 & 1.668 & 1.177 & 2.365 \\
\hline Constant & -2.149 & 0.267 & $<0.001$ & 0.117 & - & - \\
\hline \multicolumn{7}{|l|}{ The use of sodium label ${ }^{f}$} \\
\hline Income level & 0.355 & 0.143 & 0.013 & 1.426 & 1.078 & 1.886 \\
\hline Score of attitude towards salt intake ${ }^{c}$ & 0.037 & 0.007 & $<0.001$ & 1.038 & 1.025 & 1.052 \\
\hline Source of participants & -0.870 & 0.268 & 0.001 & 0.419 & 0.248 & 0.708 \\
\hline Awareness of sodium label & 0.553 & 0.272 & 0.042 & 1.739 & 1.020 & 2.964 \\
\hline Constant & -4.522 & 0.727 & $<0.001$ & 0.011 & - & - \\
\hline
\end{tabular}

${ }^{a}$ Sex, age, source of participants, educational level, household monthly income per capita, BMl $\left(\mathrm{kg} / \mathrm{m}^{2}\right)$, existing health problems, awareness of recommended daily salt intake, score of attitude towards salt intake, and salt reduction behavior were included in the model at the first step

b: Standard error

c: The score of participants towards salt intake, translated into 100 points

d: Knowing the relationship between salt and sodium

e: The behavior of usually controlling the salt intake in daily life

$f$ : Reading or checking nutrition label most of time when shopping 
on the NIP because the term "salt" is more readily comprehensible by consumers than "sodium" [22].

The reported use of the sodium label in our study was significantly lower than a similar study conducted in New York City $(50.0 \% \pm 2.2 \%)$ [19]. Moreover, in our logistic regression analysis, although we found that educational levels meant a higher awareness of the sodium label and better understanding of the relationship between salt and sodium, it did not transfer to the use of the sodium label when other factors were controlled. This means that although people with relatively high education levels were equipped with some basic knowledge and understanding of the sodium label, this knowledge did not result in them reading the NIP when shopping. This may be partially due to that health is not always the top driver of food choice.

Compared to the traditional NIP on the back of pack, front-of pack (FoP) labelling may be another effective way to convey sodium or salt information to the public. FoP labelling has been adopted by some countries to provide clearer information on nutrition information of food. In June 2013, the UK introduced a voluntary hybrid front-of-pack system that displays traffic-light colors to indicate whether the salt level is 'low' (green), 'medium' (amber) or 'high' (red), to help consumers make 'at a glance' healthier choices [23]. FoP labelling has been proven in various studies to be easier to understand and more effective for consumers in helping them to choose healthier foods $[17,18,24,25]$. In addition, FoP labelling is believed to encourage food manufactures to reformulate their foods. In the 1980s, Finland introduced legislation to require food products containing a high level of salt to carry a high salt warning [15]. As a result, food companies reformulated their products and some high salt products disappeared completely from many shops.

Assisting consumers to choose lower-salt foods should not be limited to nutrition labelling itself. Smartphone applications by various research groups to help the public choose healthier food. For instance, The George Institute for Global Health launched an 'app' called FoodSwitch in 2012 in Australia and more recently in China, which aimed to help consumers choose healthier foods. Consumers scan the barcode on the package of the food and the nutritional information is presented in traffic light colour-coded format. In addition, healthier alternatives will be listed underneath the NIP of the scanned food [26]. Furthermore, the 'app' also includes a SaltSwitch filter which allows consumers to choose foods lower in salt [27]. A recent study has shown that SaltSwitch helpful consumers choose low-salt foods [26]. Considering the increasing coverage of smartphone (58\% of Chinese people have smartphones) an app might be successful in helping people reduce their salt intake.
However, evidence has shown that the implementation of education and awareness-raising interventions alone are unlikely to be adequate in reducing population salt intake to the recommended levels [28]. New methods of health promotion on salt reduction should also be considered, for example, advocacy in schools. A study conducted in Northern China showed that integrating salt reduction into routine education for primary school children to be very successful. [29].

Several limitations existed in our study. Firstly, the survey was conducted in central districts of Beijing, where the level of awareness of sodium labels is higher than average. Secondly, as the study sample was not population-representative the results may not be representative of the whole country. Thirdly, nearly all the questions we designed were single or multiple choice. This may skew results due to a limited choice for answers on the questionnaire.

\section{Conclusions}

Our survey showed that the participants had a good understanding of the harmful effects of salt, but the awareness and use of sodium labels was very low in Beijing. Few people understand what NRV\% means on food packaging. There may be less awareness of salt and NIPs nationwide. Efforts should be taken to educate the public to understand and use the NIP better and design clearer ways of displaying such information, such as front-of pack (FoP) labelling or health-related smartphone applications to improve health and help people make better food choices.

\section{Additional file}

Additional file 1: Questionnaire. (DOCX $66 \mathrm{~kb})$

\section{Abbreviations}

Cl: Confidence Intervals; FoP: Front-of pack; NIP: Nutrition information panel; NRV\%: Nutrient reference value; SD: Mean \pm Standard Deviation; WHO: World Health Organization

\section{Acknowledgements}

We express our appreciation to all participants in this study for their participation and co-operation, to the leaders and staffs of Xicheng District Center for Disease Control and Prevention and Haidian District Administration Center for Community Health Service for their co-operation and organization in the data collection.

\section{Funding}

The study was supported by the China Center for mHealth Innovation $(\mathrm{CCmHI})$ which is hosted by The George Institute for Global Health at Peking University Health Science Center and funded by Qualcomm ${ }^{\circledast}$ Wireless Reach $^{\mathrm{TM}}$.

\section{Availability of data and materials}

The authors do not wish to share the datasets used and/or analyzed during the current study in public because it is confidential data which may be included in further study. However, some data is available from the corresponding author. 


\section{Authors' contributions}

$\mathrm{PZ}$ and WN designed this research, and gave directions for the analysis and interpretation of data for the work. YH and SY conducted the data collection with the help from $L L$ and HW. The manuscript was drafted by $\mathrm{YH}$ and critically revised by $\mathrm{LH}, \mathrm{YL}$ and other authors. YH and LH equally contributed to this research. All the authors participated the work of questionnaire design, and gave constructive suggestions for the implementation of this survey, and all reviewed the manuscript and approved the publication.

\section{Ethics approval and consent to participate}

Ethical approval was given by the medical ethics committee of Peking University Institutional Review Board (PU IRB) with the following reference number IRB00001052-16010-Exempt. The informed consent to participate in the study has been obtained from participants.

\section{Competing interests}

The authors declare that they have no competing interests.

\section{Publisher's Note}

Springer Nature remains neutral with regard to jurisdictional claims in published maps and institutional affiliations.

\section{Author details}

'The George Institute for Global Health at Peking University Health Science Center, Level 18, Tower B, Horizon Tower, No. 6, Zhichun Road, Haidian District, Beijing 100088, China. ${ }^{2}$ Department of Social Medicine and Health education, School of Public Health, Peking University, No. 38 Xueyuan Road, Haidian District, Beijing 100191, China. ${ }^{3}$ Xicheng District Center for Disease Control and Prevention, No. 38, Waidajie, Deshengmen, Xicheng District, Beijing 100120, China. ${ }^{4}$ Haidian District Administration Center for Community Health Service, No. 12, Ganjiakou community, Haidian District, Beijing, China.

Received: 14 August 2017 Accepted: 3 April 2018

Published online: 17 April 2018

\section{References}

1. Beaglehole R, Bonita R, Horton R, Adams C, Alleyne G, Asaria P, Baugh V, Bekedam H, Billo N, Casswell S, et al. Priority actions for the noncommunicable disease crisis. Lancet (London, England). 2011;377(9775): 1438-47.

2. Graudal NA, Galloe AM, Garred P. Effects of sodium restriction on blood pressure, renin, aldosterone, catecholamines, cholesterols, and triglyceride: a meta-analysis. JAMA. 1998;279(17):1383-91.

3. Hooper L, Bartlett C, Davey Smith G, Ebrahim S. Advice to reduce dietary salt for prevention of cardiovascular disease. In: Cochrane Database of Systematic Reviews: Wiley, Itd; 2004.

4. Cutler JA, Follmann D, Elliott P, Suh I. An overview of randomized trials of sodium reduction and blood pressure. Hypertension. 1991;17(1_Suppl):127.

5. He FJ, MacGregor GA. Reducing population salt intake worldwide: from evidence to implementation. Prog Cardiovasc Dis. 2010;52(5):363-82.

6. Bibbins-Domingo K, Chertow GM, Coxson PG, Moran A, Lightwood JM, Pletcher MJ, Goldman L. Projected effect of dietary salt reductions on future cardiovascular disease. N Engl J Med. 2010;362(7):590-9.

7. Cobiac $L$, Vos T, Veerman JL. Cost-effectiveness of interventions to reduce dietary salt intake. Heart. 2010;96(23):1920-5.

8. Webster J, Trieu K, Dunford E, Hawkes C. Target salt 2025: a global overview of National Programs to encourage the food industry to reduce salt in foods. Nutrients. 2014:6(8):3274-87.

9. Wang M, Moran AE, Liu J, Qi Y, Xie W, Tzong K, Zhao D. A Meta-Analysis of Effect of Dietary Salt Restriction on Blood Pressure in Chinese Adults. Glob Heart. 2015;10(4):291-299.e296.

10. Anderson CA, Appel L, Okuda N, Brown IJ, Chan Q, Zhao L, Ueshima H, Kesteloot H, Miura K, Curb JD, et al. Dietary sources of sodium in China, Japan, the United Kingdom, and the United States, women and men aged 40 to 59 years: the INTERMAP study. J Am Diet Assoc. 2010;110(5):736-45.

11. WHO. Guideline: Sodium intake for adults and children. Geneva: World Health Organization (WHO); 2012

12. Neal B, Webster J, Trieu K, Dunford E, Hawkes C. Target salt 2025: a global overview of national programs to encourage the food industry to reduce salt in foods. JMIR mHealth uHealth. 2014;6(8):3274-87.
13. Trieu K, Neal B, Hawkes C, Dunford E, Campbell N, Rodriguez-Fernandez R, Legetic B, McLaren L, Barberio A, Webster J. Salt reduction initiatives around the world - a systematic review of progress towards the global target. PLoS One. 2015;10(7):e0130247.

14. Campbell N, Legowski B, Legetic B, Ferrante D, Nilson E, Campbell C, L'Abbe $M$. Targets and timelines for reducing salt in processed food in the Americas. J Clin Hypertens (Greenwich). 2014;16(9):619-23.

15. Pietinen $P$, Valsta LM, Hirvonen T, Sinkko H. Labelling the salt content in foods: a useful tool in reducing sodium intake in Finland. Public Health Nutr. 2008;11(4):335-40.

16. Cobb LK, Appel LJ, Anderson CA. Strategies to reduce dietary sodium intake. Curr Treat Options Cardiovasc Med. 2012;14(4):425-34.

17. Goodman S, Hammond D, Hanning R, Sheeshka J. The impact of adding front-of-package sodium content labels to grocery products: an experimental study. Public Health Nutr. 2013:16(3):383-91.

18. Okuda N, Nishi N, Ishikawa-Takata K, Yoshimura E, Horie S, Nakanishi T, Sato $\mathrm{Y}$, Takimoto H. Understanding of sodium content labeled on food packages by Japanese people. Hypertens Res. 2014;37(5):467-71.

19. Elfassy $T$, Yi S, Eisenhower D, Lederer A, Curtis CJ. Use of sodium information on the nutrition facts label in New York City adults with hypertension. J Acad Nutr Diet. 2015;115(2):278-83.

20. Wang SS, Lay S, Yu HN, Shen SR. Dietary Guidelines for Chinese residents (2016): comments and comparisons. J Zhejiang Univ Sci B. 2016;17(9):649-56.

21. Standards CAIF. Guidelines On Nutrition Labelling CAC/GL 2-1985. In: Food and Agriculture Organization of the United Nations, World Health Organization; 2015. p. 10.

22. Population Health Division. Technical guidance on nutrition labelling. UK: Department of Health, GOV.; 2016.

23. Magnusson R, Reeve B. Food reformulation, responsive regulation, and "regulatory scaffolding": strengthening performance of salt reduction programs in Australia and the United Kingdom. Nutrients. 2015;7(7):5281-308.

24. Feunekes GI, Gortemaker IA, Willems AA, Lion R, van den Kommer M. Frontof-pack nutrition labelling: testing effectiveness of different nutrition labelling formats front-of-pack in four European countries. Appetite. 2008; 50(1):57-70

25. McLean R, Hoek J, Hedderley D. Effects of alternative label formats on choice of high- and low-sodium products in a New Zealand population sample. Public Health Nutr. 2012;15(5):783-91.

26. Dunford E, Trevena H, Goodsell C, Ng KH, Webster J, Millis A, Goldstein S, Hugueniot O, Neal B. FoodSwitch: a mobile phone app to enable consumers to make healthier food choices and crowdsourcing of National Food Composition Data. JMIR Mhealth Uhealth. 2014;2(3):e37. https://doi. org/10.2196/mhealth.3230.

27. Eyles H, McLean R, Neal B, Doughty RN, Jiang Y, Ni Mhurchu C. Using mobile technology to support lower-salt food choices for people with cardiovascular disease: protocol for the SaltSwitch randomized controlled trial. BMC Public Health. 2014;14:950.

28. Trieu K, McMahon E, Santos JA, Bauman A, Jolly KA, Bolam B, Webster J. Review of behaviour change interventions to reduce population salt intake. Int J Behav Nutr Phys Act. 2017;14(1):17.

29. He FJ, Wu Y, Feng XX, Ma J, Ma Y, Wang H, Zhang J, Yuan J, Lin CP, Nowson C, et al. School based education programme to reduce salt intake in children and their families (school-EduSalt): cluster randomised controlled trial. BMJ (Clinical research ed). 2015;h770:350

\section{Ready to submit your research? Choose BMC and benefit from:}

- fast, convenient online submission

- thorough peer review by experienced researchers in your field

- rapid publication on acceptance

- support for research data, including large and complex data types

- gold Open Access which fosters wider collaboration and increased citations

- maximum visibility for your research: over $100 \mathrm{M}$ website views per year

At BMC, research is always in progress.

Learn more biomedcentral.com/submissions 